\title{
Water absorption of epoxy/glass fiber/organo-montmorillonite nanocomposites
}

\author{
W. S. Chow* \\ School of Materials and Mineral Resources Engineering, Engineering Campus, Universiti Sains Malaysia, Nibong Tebal \\ 14300 Pulau Pinang, Malaysia
}

Received 28 November 2006; accepted in revised form 2 January 2007

\begin{abstract}
The epoxy/glass fiber/organo-montmorillonite (OMMT) nanocomposites were prepared by hand lay up method. In the previous work, the flexural and morphological properties of the epoxy/glass fiber/OMMT were studied. In this work, the epoxy nanocomposites were characterized by X-ray diffraction (XRD), differential scanning calorimetry (DSC) and water absorption tests. The exfoliation of OMMT in epoxy/glass fiber nanocomposites was detected by XRD. DSC results showed that the glass transition temperature $\left(T_{g}\right)$ of epoxy was increased slightly in the presence of OMMT. Water uptake of epoxy was reduced by the addition of glass fiber and OMMT. The decrease of water absorption in epoxy is attributed to the increasing of tortuosity path for water penetration in the epoxy composites by the hybrid of glass fiber and OMMT.
\end{abstract}

Keywords: polymer composites, epoxy, glass fiber, organo-montmorillonite, water absorption

\section{Introduction}

Epoxy resin represents some of the highest performance resin due to the mechanical properties and resistance to environmental degradation, which leads to their almost exclusive use in aircraft components. Epoxies are defined as cross-linked polymers in which the cross-linking is derived from reactions of the epoxy group. Epoxy resin usually used in coating industry as surface coating materials which combine toughness, flexibility, adhesion and chemical resistance. In addition, epoxy resin can also be used in both laminating and molding techniques to make fiber reinforcement with better mechanical strength, chemical resistance and electrical insulating properties [1]. Epoxy resin also used with reinforcing fibers for advanced composites application. This is due to the capability of epoxy resin that showed good adhesion to the embedded fiber [2].
Clays have received much attention as reinforcing materials for polymers because of their potentially high aspect ratio and unique intercalation/exfoliation characteristics. Montmorillonite (MMT) frequently exhibit unexpected properties including reducing gas permeability, improved solvent resistance, and superior mechanical and enhance flameretardant properties [2]. Typically, clay minerals have a layered silicate structure about $1 \mathrm{~nm}$ in thickness and a high aspect ratio ranging from 100 to 1500 [3]. Naturally occurring montmorillonite is incompatible with most polymers because of its hydrophilic nature. Ion exchange is widely practiced to modify the montmorillonite's surface to increase its compatibility with mostly hydrophobic polymers. Introduction of organic ions may decrease the Van der Waals interactions between the silicate layers and hence increase the interlamellar spacing [4].

Glass fiber is a part of reinforcing materials for reinforced plastics based on single filaments of

*Corresponding author, e-mail: shyang@eng.usm.my

(C) BME-PT and GTE 
glass ranging in diameter from 3 to 19 micrometers. Glass fibers show good performance and play a main function in playground equipment, recreational items, piping for corrosive chemicals, and many other common applications. The cost of the glass fiber is considerably lower than the cost of carbon-based fibers [5]. Fiber reinforced composites can be explained as the strength of fibers in fibrous composites exceeds considerably the strength of the matrix. Fibers such as short aramid $(\mathrm{AF})$, glass $(\mathrm{GF})$ or carbon $(\mathrm{CF})$ fibers are used in order to increase the creep resistance and the compressive strength of the polymer matrix system used [6]. The addition of fibers is to ensure the strength of the material while the matrix helps to keep the shape of the composite.

Thermoset layered silicate nanocomposite may synthesize as intercalated/exfoliated structure. It is depending on stacked layer structure of the clay is maintained after processing with the polymer matrix. Although thermoset nanocomposite often prepared by swelling organically modified clay with a monomer precursor, it may be advantageous if intercalation and/or exfoliation can be achieved by combining suitable functionalized monomer/ pre-polymers with a native layered silicate such as sodium montmorillonite [7]. The ideal case in order to maximize the stiffness and thermal properties of the epoxy-clay nanocomposite is through full exfoliation and well dispersed of clay platelets in the composites [8].

The preparation method used for mixing the epoxy resin with clay is in situ intercalative polymerization method. In this method, the layered silicate is swollen within the monomer solution so the polymer formation can occur between the intercalated sheets. Polymerization can be initiated either by heat or by diffusion of a suitable initiator or by an organic initiator or catalyst fixed through cation exchange the interlayer before the swelling start to occur [9]. The most important manufacturing process of composites applied to aerospace industry is the hand lay-up of prepregs and autoclave cure. The hand lay-up still persists as the method in use for more than half of all advanced aerospace composites structures attributed to the flexibility of this technique which allows the manufacturing of varieties shapes. Additionally hand lay-up does not require large capital investment [10].

Epoxy resins are very attractive due to high strength and stiffness, high temperature resistance, low shrinkage, low volatility and etc. However, the epoxy resin absorbs high degree of moisture which in turn degrades the functional, structural and mechanical properties of the composites [11]. In our previous studies, it was found that the optimum loading of OMMT in epoxy/glass fiber nanocomposites is attained at $3 \mathrm{wt} \%$ [12]. The combination of glass fiber and organo-montmorillonite could give a synergistic effect on the improvement of mechanical properties for epoxy through hand-lay up technique. Consequently, the objective of this continuous research work is to enhance the water resistance of epoxy by the combination of glass fiber and organo-montmorillonite.

\section{Experimental}

\subsection{Materials}

Epoxy resin used in this study was diglycidyl ether bisphenol A [(DGEBA) DER 331] provided by Dow Chemical. It was used in combination with cycloaliphatic amine hardener (HY 2964) supplied by Ciba Geigy. The glass fiber used was in the form of chopped strand mat (CSM). The organo-montmorillonite (OMMT) used in this study was commercially available modified montmorillonite layered silicate (Nanomer I.30E) from Nanocor, USA.

\subsection{Sample preparation}

\subsubsection{Epoxy/OMMT mixture preparation}

The ratio between epoxy and hardener was $10: 6 \mathrm{wt} / \mathrm{wt}$. Then, $3 \mathrm{wt} \%$ of OMMT was added to the DGEBA resin. The mixture was then stirred using a mechanical stirrer at $100 \mathrm{rpm}$. The stirring process was continued until all the OMMT powder was well dispersed in the epoxy resin system in about 10 minutes. Next, hardener was added into the mixture and the stirring process continued for about 5 min.

\subsubsection{Hand lay-up method}

Four plies $\left(17 \times 17 \mathrm{~cm}^{2}\right)$ of CSM were cut. The first ply of CSM was placed on an aluminium plate which had been covered with a polypropylene (PP) film. Next, epoxy resin was applied on the glass fiber mat. It is important to ensure that the resin wets the entire surface of glass fiber. Then, addi- 
tional resin was applied and the second ply was laminated until complete wetting. This procedure was repeated until all the plies were superimposed, and a PP film was applied on top of the laminate glass fiber. Then, the sample was pressed with a metal roller from one side to the other. The purpose of pressing is to attain the desired thicknesses of approximately $3.2 \mathrm{~mm}$. Then, an aluminium plate was placed on the top of the sample. The laminated samples were placed in an oven for complete curing process at $100^{\circ} \mathrm{C}$ for $60 \mathrm{~min}$.

\subsection{Sample characterization}

X-ray Diffraction (XRD) was performed with a Diffraktometer D5000 Siemens (Kristaloflex) Model. The X-ray beam was equipped with a $\mathrm{CuK} \alpha$ $(\lambda=0.1504 \mathrm{~nm})$ radiation operated at $40 \mathrm{kV}$ and $30 \mathrm{~mA}$. The scanning speed and step size were $1 \%$ min and $0.02^{\circ}$, respectively. The diffraction patterns were collected between $1^{\circ}$ and $10^{\circ}$. The interlayer spacing of the OMMT was derived from the peak position ( $\mathrm{d}_{001}$-reflection) in the XRD diffractograms according to the Bragg equation $(\lambda=$ $2 d \sin \theta)$.

The glass transition temperature $\left(T_{g}\right)$ of epoxy/glass fiber/OMMT nanocomposites was determined by a Perkin Elmer (DSC 6). The test was performed at a heating and cooling rate of $10^{\circ} \mathrm{C} / \mathrm{min}$ in nitrogen $\left(\mathrm{N}_{2}\right)$ atmosphere. The samples were heated from $30-160^{\circ} \mathrm{C}$, and held at $160^{\circ} \mathrm{C}$ for $1 \mathrm{~min}$. Then, the samples were cooled from $160-30^{\circ} \mathrm{C}$.

Water absorption of epoxy composites was performed according to ASTM D570. Specimens were dried at $80^{\circ} \mathrm{C}$ in a vacuum oven until a constant weight was attained. Then, they were immersed in water in a thermostated stainless steel water bath at $30^{\circ} \mathrm{C}$. Weight gains were recorded by periodic removal of the specimens from the water bath and weighing on a balance with a precision of $1 \mathrm{mg}$. The percentage gain at any time $t\left(M_{t}\right)$ as a result of moisture absorption was determined by Equation (1):

$M_{t}=\frac{W_{w}-W_{d}}{W_{d}} \cdot 100$

where $W_{d}$ and $W_{w}$ denote the weight of dry material (the initial weight of materials prior to exposure to the water absorption) and weight of materials after exposure to water absorption, respectively.

\section{Results and discussion}

Figure 1 shows the X-ray diffractogram of OMMT powder and epoxy/glass fiber/OMMT nanocomposites. The corresponding pattern of the epoxy nanocomposites is in the range of the diffraction angle $2 \theta=1-10^{\circ}$. The basal spacing for OMMT powder is $2.03 \mathrm{~nm}$. An almost complete disappearance of the characterization peak of OMMT in epoxy/glass fiber/OMMT was detected. This indicates that the silicate platelets in the epoxy matrix were exfoliated. The absence of basal reflection in nanocomposites indicates good exfoliation of silicate platelets in epoxy matrix. The formation of exfoliation or intercalation of silicate platelets is due to the reaction of OMMT with amine hardener [13]. Ratna et al. [14] also reported that the absence of $d_{100}$ peak in the X-ray spectrum of all binary and ternary epoxy/layered silicate systems indicates exfoliation of clay.

Figure 2 shows the DSC thermograms of epoxy/ glass fiber and epoxy/glass fiber/OMMT nanocomposites. The glass transition temperature $\left(T_{g}\right)$ value

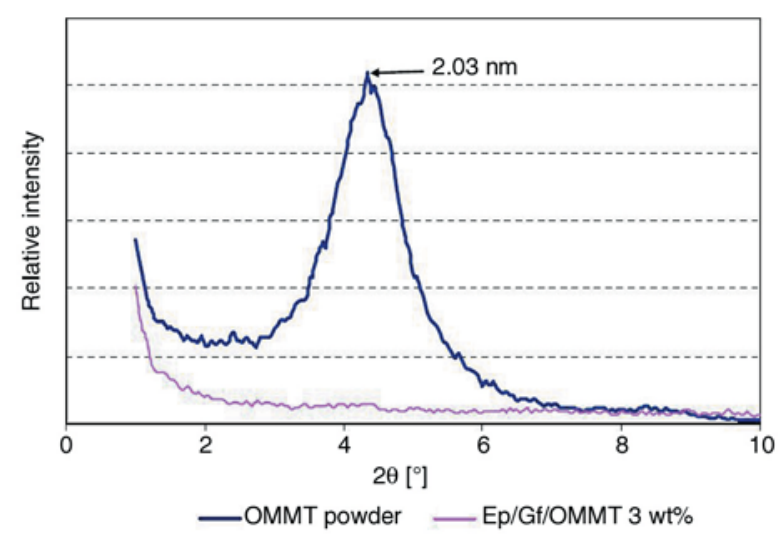

Figure 1. X-ray diffractograms patterns of the OMMT and epoxy/glass fiber/OMMT nanocomposites

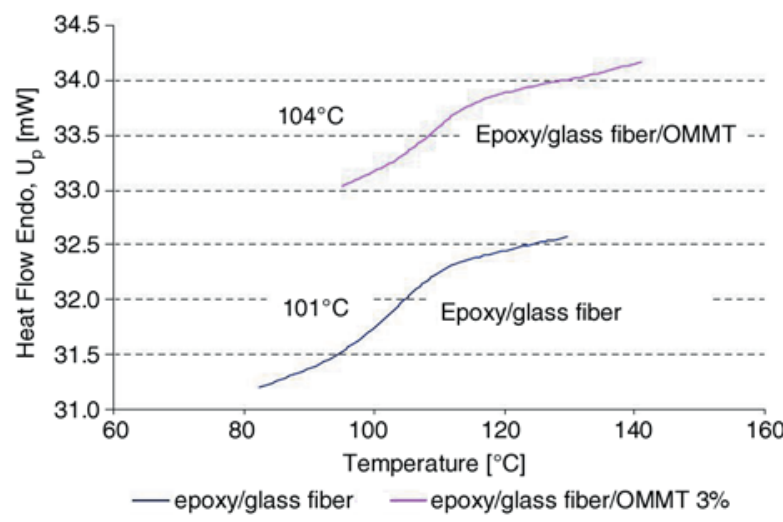

Figure 2. DSC thermograms of epoxy/glass fiber composites and epoxy/glass fiber/OMMT nanocomposites 
of epoxy/glass fiber and epoxy/glass fiber/OMMT is $101^{\circ} \mathrm{C}$ and $104^{\circ} \mathrm{C}$, respectively. Epoxy/glass fiber/OMMT nanocomposite recorded slightly higher $T_{g}$ value than that of epoxy/glass fiber composite. The presence of the alkyl ammonium ions in OMMT might catalyzes the polymerization within the clay galleries, which could further promote the inter-gallery polymerization. This could leads to a better OMMT dispersion and exfoliation. The slightly higher $T_{g}$ value maybe correlate to the exfoliation of OMMT in the epoxy/glass fiber composites. The slightly increment of $T_{g}$ value of epoxy/glass fiber/OMMT nanocomposites also maybe due to the interaction of OMMT and glass fiber in the epoxy network which could restrict the chain mobility. This can be attributed to confinement of polymer chain as a result of intercalation into the interlayer gallery of the clay [14].

Figure 3 shows water uptake of epoxy, epoxy/glass fiber composites and epoxy/glass fiber/OMMT nanocomposites. The water absorption of all epoxy samples was reached saturation after 35 days. This indicates that the absorption reaches quasi-equilibrium condition. The water absorption will recommence after quasi-equilibrium [15]. However, water molecules can only stay in micro-voids and form clusters. The water cluster might be bound due to the large form of cluster. Only external water molecules of clusters may interact with the polymer. The water molecules might be free molecules which have diffused initially during immersion. Water absorption will reach a real equilibrium when all micro-voids are filled.

It can be seen that the water absorption of epoxy is relatively higher compared to epoxy/glass fiber composites and epoxy/glass fiber/OMMT nano-

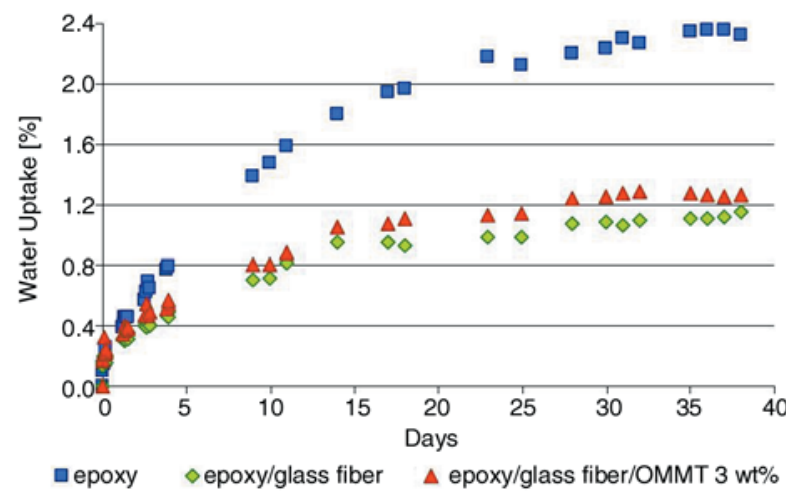

Figure 3. Water uptake on epoxy, epoxy/glass fiber composites, and epoxy/glass fiber/OMMT nanocomposites composites. The water uptake of epoxy is approximately $2.3 \%$ upon subjected to water absorption test for 40 days. The water sorption behavior is considered to depend on free volume properties, type and concentration of polar groups in the epoxy system [16]. According to Becker et al. [16], the equilibrium water uptake of the epoxy/layered silicate nanocomposites was reduced compared to the neat epoxy system. Water uptake may be due to the capability of the water molecules to penetrate through the epoxy network. The diffusion of water occurs in epoxy resin is attributed to the nature of the polymer which shows strong interaction with water. In epoxy matrices, water molecules couple strongly with hydrophilic functional groups such as hydroxyl or amine in epoxy resin. The water molecules might interact with epoxy molecules by forming hydrogen bonding with hydrophilic groups [17]. The absorption of water can be attributed to the affinity of the functional groups of the epoxies which having high polarity towards water molecules [18]. Water can be existence in two forms (i) free water which will fill the micro-cavities of the network structure in the composites, and (ii) strong interactions occur within the water molecules and polar group of epoxy resin [19].

From Figure 3, it can be seen that the water uptake of epoxy/glass fiber composites is about $1.1 \%$ after subjected to water absorption for 40 days. Fiber reinforcement in epoxy matrix could reduce the penetration of water in composites. However, the incorporation of OMMT in the epoxy/glass fiber composite slightly increases the water uptake. The epoxy/glass fiber/OMMT nanocomposites specimens recorded water absorption value at $1.25 \%$ upon 40 days. This might be due to the octadecyl onium ion on OMMT surface which could react with water. The $\mathrm{N}-\mathrm{H}^{+}$groups of alkylammonium ions are hydrogen-bonded to water molecules by donating protons to the water-oxygen atoms. The ammonium group may form up to three hydrogen bonds with water molecules. Induction of ammonium group may increase the acid strength of the hydrating water molecules and latter may donate protons to additional water molecules [20].

\section{Conclusions}

Epoxy/glass fiber/OMMT hybrid nanocomposites prepared by hand-lay up technique showed exfoliation characteristics and slightly enhancement in 
glass transition temperature. The water resistance properties of epoxy were improved by the addition of both glass fiber and OMMT, which is maybe attributed to the increasing of the tortuosity path for water penetration.

\section{References}

[1] Wilkinson S. B., White J. R.: Thermosetting short fibre reinforced composites. in 'Short fibre-polymer composites' (eds.: De S. K. and White J. R.), Woodhead Publishing Limited, Cambridge, 54-81 (1996).

[2] Zhou Y., Pervin F., Biswas M. A., Rangari V. K., Jeelani S.: Fabrication and characterization of montmorillonite clay-filled SC-15 epoxy. Materials Letters, 60, 869-873 (2006).

[3] Guo B., Jia D., Cai C.: Effects of organo-montmorillonite dispersion on thermal stability of epoxy resin nanocomposites. European Polymer Journal, 40, 1743-1748 (2004).

[4] Kornmann X., Rees M., Thomann Y., Necola A., Barbezat M., Thomann R.: Epoxy-layered silicate nanocomposites as matrix in glass fiber-reinforced composites. Composites Science and Technology, 65, 2259-2268 (2005).

[5] Hyer M. W.: Stress analysis of fiber-reinforced composite materials. McGraw-Hill, USA, 578-699 (1998).

[6] Friedrich K., Zhang Z., Schlarb A. K.: Effects of various fillers on the sliding wear of polymer composites. Composites Science and Technology, 65, 2329-2343 (2005).

[7] Rodlert M., Plummer C. J. G., Garamszegi L., Leterrier Y., Grünbauer H. J. M., Manson J.-A. E.: Hyperbranched polymer/montmorillonite clay nanocomposites. Polymer, 45, 949-960 (2004).

[8] Jordan J., Jacob K. I., Tannenbaum R., Sharaf M. A., Jasiuk I.: Experimental trends in polymer nanocomposites - a review. Materials Science and Engineering, A 393, 1-11 (2005).

[9] Ray S. S., Okamoto M.: Polymer/layered silicate nanocomposites: a review from preparation to processing. Progress in Polymer Science, 28, 1539-1641 (2003).
[10] Jones F. R.: Matrices: Epoxy resins. in 'Handbook of polymer-fibre composites' (eds.: Jones F. R.) Polymer Science \& Technology Series, Longman Scientific \& Technical, England, 69-129 (1994).

[11] Kim J-K., Hu C., Woo R. S. C., Sham M-L.: Moisture barrier characteristics of organoclay-epoxy nanocomposites. Composites Science and Technology, 65, 805-813 (2005).

[12] Mazlan N., Abu Bakar A., Chow W. S.: Effects of organo-montmorillonite on the mechanical and morphological properties of epoxy/glass fiber composites. Polymer International, DOI: 10.1002/PI.2146, article in press (2007).

[13] Siddiqui N. A., Woo R. S. C., Kim J-K., Leung C. C. K., Munir A.: Mode I interlaminar fracture behaviour and mechanical properties of CFRPs with nanoclayfilled epoxy matrix. Composites: Part A, 38, 449-460 (2007).

[14] Ratna D., Becker O., Krishnamurthy R., Simon G. P., Varley R. J.: Nanocomposites based on a combination of epoxy resin, hyperbranched epoxy and a layered silicate. Polymer, 44, 7449-7457 (2003).

[15] Popineau S., Rondeau-Mouro C., Sulpice-Gaillet C., Shanahan M. E. R.: Free/bound water absorption in an epoxy adhesive. Polymer, 46, 10733-10740 (2005).

[16] Becker O., Varley R. J., Simon G. P.: Thermal stability and water uptake of high performance epoxy layered silicate nanocomposites. European Polymer Journal, 40, 187-195 (2004).

[17] Zhou J., Lucas J. P.: Hygrothermal effects of epoxy resin. Part 1: The nature of water in epoxy. Polymer, 40, 5505-5512 (1999).

[18] Karad S. K., Attwood D., Jones F. R.: Moisture absorption by cyanate ester modified epoxy resin matrices, Part V: Effect of resin structure. Composites: Part A, 36, 764-771 (2005).

[19] Han S. O., Dzarl L. T.: Water absorption effects in hydrophilic polymer matrix of carboxyl functionalized glucose resin and epoxy resin. European Polymer Journal, 39, 1791-1799 (2003).

[20] Yariv S.: Introduction to organo-clay complexes and interactions. in 'Organo-clay complexes and interactions' (eds.: Yariv S. and Cross H.) Marcel Dekker, New York, 40-112 (2002). 